\title{
Modern suspension systems for automotive vehicles and their test methods
}

\author{
Lukasz Konieczny ${ }^{1}$, Rafal Burdzik ${ }^{2}$ \\ Silesian University of Technology, Faculty of Transport, Gliwice, Poland \\ ${ }^{1}$ Corresponding author \\ E-mail: ${ }^{1}$ lukasz.konieczny@polsl.pl, ${ }^{2}$ rafal.burdzik@polsl.pl \\ Received 26 September 2017; accepted 5 October 2017 \\ DOI https://doi.org/10.21595/vp.2017.19238
}

Check for updates

\begin{abstract}
This article provides a discussion on various solutions used in modern suspension systems of automotive vehicles. The mechanical dependent suspension system and some solution of adaptive, semi-active and active suspension system has been described. The paper also presents shortly test methods used to evaluation of technical conditions of this system.
\end{abstract}

Keywords: modern suspension system, diagnostics of car suspension system.

\section{Introduction}

Automotive suspension systems are dynamic systems which directly affect safety and comfort of the vehicle user as well as of other road traffic participants. The technical condition of this system determines the vehicle behaviour under different driving conditions, being particularly relevant for such parameters as braking distance, grip, acceleration or following a curvilinear track while driving on different road pavements. On account of such an important influence on safety, suspension systems are subject to periodical inspections in the course of the vehicle service, as required by the applicable provisions contained in the Journal of Laws of 2015, item 776. Besides the assessment of play and organoleptic evaluation of the technical condition of the suspension system components, it is increasingly common (even required at district vehicle inspection stations) that dedicated stations are used to assess the technical condition of suspension systems (mainly shock absorbers) by application of vibratory methods. However, both the less popular Boge method and the commonly applied EUSAMA method are flawed and undoubtedly require improvements, particularly in light of the dynamic evolution of suspension subunits (semi-active, active suspension systems etc.) [1-9].

\section{Suspension systems}

The role of spring components in conventional suspensions fulfils generally coil springs (less often torsion bars and leaf springs) [1]. This element has constant spring characteristics. Independent kind of suspension -McPherson strut is showed on Fig. 1.

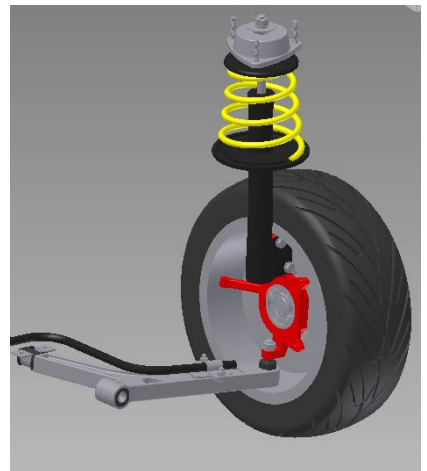

Fig. 1. Conventional independent suspension - McPherson strut 
In order to meet increasingly demanding requirements, contemporary automotive suspension systems have in fact become highly complex mechatronic units which enable parameters of vibroinsulation systems to be changed. Actuating elements make it possible to adjust parameters connected, for instance, with rigidity within a specific range of values. An example of such a solution is an additional hydroactive suspension system zone that can be coupled or uncoupled with the hydraulic suspension of the given vehicle axle. However, the most typical solution involves changing of damping parameters. One may observe continuous evolution of semi-active, active and adaptive suspension systems (Fig. 2). Unlike passive suspension systems, all the aforementioned types enable adapting the suspension parameters to individual road conditions and driving styles. Suspension control systems adjust the characteristics of elastic and damping components to match pre-set criteria, such as comfort or sport driving modes, for instance.

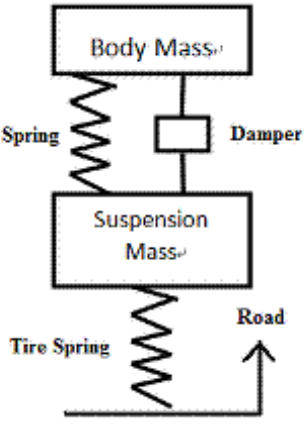

a) Passive

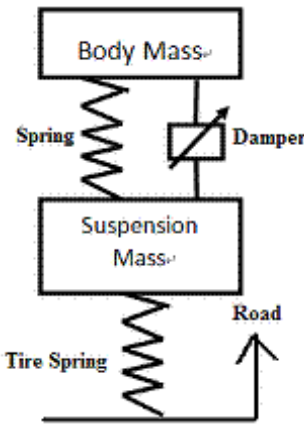

b) Semi-active

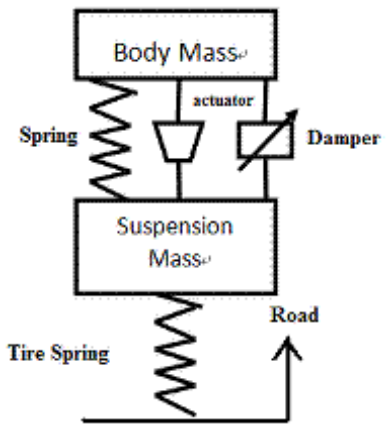

c) Active

Fig. 2. Automotive suspension systems [10]

Application of different suspension design solutions affects many significant parameters, one of which is the system's free vibration frequency. For a system with classical passive mechanical suspension (spring), the system's free vibration frequency declines as load rises. In pneumatic suspension systems (constant gas volume springs), also frequency decreases as the load increases in a system featuring such a spring, however, not as considerably as in the system referred toFig. 3.

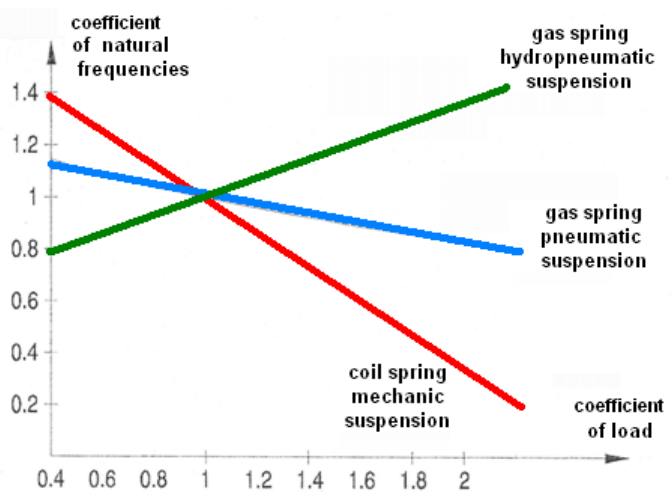

Fig. 3. Changes in free vibration frequency for different suspension systems [8]

In mechanical suspension systems, as the load increases, static compression of the elastic element rises, whereas in cases of total loading, the range of available wheel travel on compression is reduced (see Fig. 4), this being one of the most considerable disadvantages of similar suspension systems. Therefore, one typically needs progressive characteristics to be obtained in spring-type suspension systems, which is achieved through appropriate design solutions (two parallel springs etc.). 
In order to be able to control and generate forces in a system comprising suspension of an automotive vehicle, one must apply complicated control algorithms (control principles, such as e.g. SkyHook, which optimise damping parameters to match the criterion of velocity reduction for sprung masses). What proves to limit these solutions is the time lag (inertia) of the mechatronic system's actuating elements.

Among the most advanced solutions applied in active suspension systems, one should highlight MPCD (Model Predictive Controller) whose control algorithm uses information about the road profile (special sensors enable profile calibration for the road in front of the vehicle), and this kind of information makes it possible to calculate and match suspension system parameters to the input function in due advance.

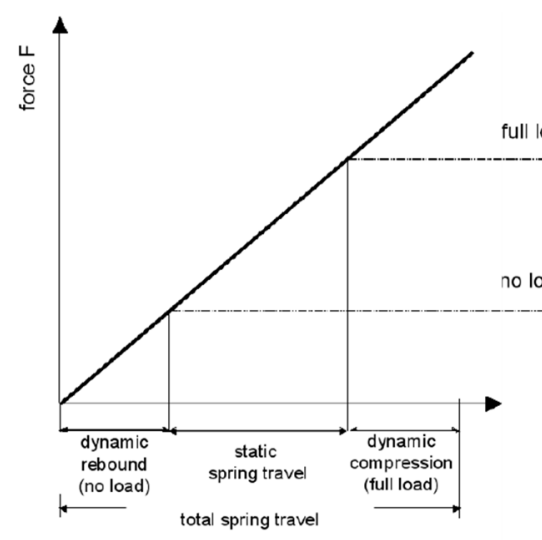

a)

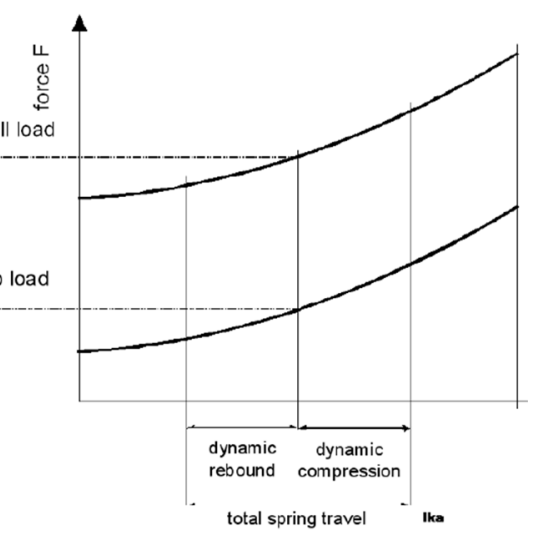

b)

Fig. 4. Suspension system without a) mechanical and with static deflection compensation b) pneumatic or hydropneumatic [8]

Controllable solutions are typically based on mechatronic systems which control the operation of shock absorbers of adjustable characteristics (shock absorbers featuring a control valve that adjusts the fluid flow through what is referred to as by-passes or ones that use magnetorheological fluid). The solution which consists in using suspension systems of adjustable parameters does not significantly increase the complexity of the mechanical suspension system (shock absorber, spring and suspension arms). Some examples of this solution include the following shock absorbers:

- Sachs CDC (Continuous Damping Control), also known as Skyhook or IDS and used in cars of such brands as WV, BMW, GM, Opel, Fiat, Porsche, Ferrari, Maserati. This solution is based on an electronic system of adjustable vibration damping by means of shock absorbers featuring two solenoid valves (ensuring separate control of compression and tension).

- Bilstein ADS (Adaptive Damping Control) - solution used by Mercedes-Benz in models such as S, E, CLS and SL, CL, SLK. It also relies on the electronic system of adjustable vibration damping by means of shock absorbers with solenoid valves.

- Monroe CES (Continuously Controlled Electronic Suspension) - also known as Four-C and used in Volvo S60R/V70R and S80. This solution is also based on the electronic system of adjustable vibration damping with shock absorbers featuring solenoid valves.

- Delphi MagnetiRide - solution commonly referred to as Magnetic Ride Control and used in cars manufactured by the GM corporation as well as in Chevrolet Corvette. It is based on utilisation of properties of magnetorheological fluid. Under the impact of magnetic field, the system adapts its physical properties, thus enabling adjustable setting of the shock absorber's damping parameters in time shorter than $1 \mathrm{~ms}$. Instead of the solenoid valve, this solution features a set of ducts of appropriate diameter used to supply the magnetorheological fluid. Control of the shock absorber operation is not complicated, since the dependence between damping force and the value of intensity of the current which generates the magnetic field is in fact linear. The range 
of changes is considerably large, and it makes it possible to generate force being 14 times higher than that generated under zero power supply conditions.

- Kayaba DRC (Dynamic Ride Control) - solution used in Audi RS6 Quattro. It is based on a hydraulic coupling between shock absorbers of individual wheels and valves that control the fluid flow.

- PDC (Pneumatic Damping Control) shock absorbers used in Audi Allroad. This solution is known of the specific design assuming that parameters of the pneumatic suspension spring control settings of the corresponding shock absorber characteristics. The suspension spring's air pressure adjusts settings of the dedicated PDC valve installed in the shock absorber.

There are also even more expanded systems, making use of solutions based on pneumatic or hydraulic systems. Pneumatic suspension systems are installed in such car models as:

- Jaguar XJ featuring the CATS (Computer Active Technology Suspension) system. Mercedes-Benz models E and S equipped with the AIRmatic suspension system,

- Volkswagen Phanteon with the 4CL system.

In the above solutions, a constant gas volume spring (enabling adjustment of vehicle clearance both while driving and at a stop) cooperates with shock absorbers of adjustable damping characteristics.

The mass of gas in gas springs used in hydropneumatic suspension systems [11-13] installed in passenger vehicles is constant. This solution has mainly been used by Citroen in such models as:

- BX, XM, Xantia and optionally in C5 and C6.

These suspension systems use constant gas mass springs cooperating with hydraulic cylinders. Pressure-controlled elements of the hydraulic suspension system enable adjustment of the vehicle clearance value.

\section{Diagnostic methods}

It should be noted that the most commonly used method in Poland of testing shock absorbers built into the car is the EUSAMA method. The BOGE, MAHA, HOFFMAN types currently have limited uses. Other methods proposed by Beissbarth and Hunter Engineering Company, despite their many advantages, have not been widely used in Vehicle Control Stations.

In summary, modern methods of assessing the technical condition of suspensions of passenger cars, and in particular of shock absorbers, are based on vibration tests with harmonic kinematic excitation. The development of methods is directed at obtaining additional diagnostic information (not only the vibration amplitude in the resonance), such as, for example, the phase angle and the unambiguous association of this information with the vehicle mass distribution (the ratio of sprung and unsprung masses) [6, 14-21].

\section{Conclusions}

It should be noted that one of the most popular suspension system solutions used in passenger car is the independent suspension with coil springs. It is both relatively cheap and considerably reliable in terms of failure frequency. The alternative towards for mechanical systems are nonconventional pneumatic and hydropneumatic suspension systems. In pneumatic systems, constant gas volume springs are used and clearance is controlled by changing the gas quantity inside the system, whereas in a hydropneumatic system featuring a constant gas mass spring, clearance is adjusted by increasing the quantity of liquid in hydraulic cylinders. Application of non-conventional suspension systems requires development and improvement of diagnostic methods used in assessment of technical condition of the suspension. 


\section{References}

[1] Balamurugan L., Jancirani J., Eltantawie M. A. Generalized magnetorheological (MR) damper model and its application in semi-active control of vehicle suspension system. International Journal of Automotive Technology, Vol. 15, Issue 3, 2014, p. 419-427.

[2] Burdzik R., Konieczny L., Adamczyk B. Automatic control systems and control of vibrations in vehicles car. Communications in Computer and Information Science, Vol. 471, 2014, p. 1865-929.

[3] Burdzik R., Konieczny L., Lazarz B. Influence of damping characteristics changes on vehicles vibration research. 19th International Congress on Sound and Vibration, Lithuania, 2012.

[4] Burdzik R., Konieczny Ł. Application of vibroacoustic methods for monitoring and control of comfort and safety of passenger cars. Solid State Phenomena, Vol. 210, 2013, p. 20-25.

[5] Burdzik R., Konieczny L. New methods for identification of technical condition of vehicle suspension in term of driving safety. Some actual issues of traffic and vehicle safety. Faculty of Transport, Silesian University of Technology, Gliwice, 2013.

[6] Cao D. P., Rakheja S., Su C. Y. Roll plane analysis of interconnected hydro-pneumatic suspension struts. Proceedings of the ASME Design Engineering Division 2005, p. 133-142.

[7] Dixon J. C. The Shock Absorber Handbook Society of Automotive Engineers Inc., Warrendale, PA, 1999.

[8] Gillespie T. D. Fundamentals of Vehicle Dynamics. SAE International, 1992.

[9] Konieczny L. Determination of the damping characteristics of hydropneumatic strut taking into account the chosen parameters. Scientific Journal of Silesian University of Technology, Series Transport, Vol. 69, 2010, p. 85-89.

[10] Konieczny $\mathbf{t}$. The statistical analysis of damping parameters of hydraulic shock absorbers. Diagnostic, Vol. 15, Issue 1, 2014, p. 49-52.

[11] Giliomee C. L. Analysis of a Four State Switchable Hydro-Pneumatic Spring and Damper System. University of Pretoria, 2005.

[12] Snamina J., Kowal J., Orkisz P. Active suspension based on low dynamic stiffness. Acta Physica Polonica A, Vol. 123, Issue 6, 2013, p. 1118-1122.

[13] Ho C., Lang Z. Q., Sapinski B. Vibration isolation using nonlinear damping implemented by a feedback-controlled MR damper. Smart Materials and Structures, Vol. 22, Issue 10, 2013, p. 105010.

[14] Konieczny L., Burdzik R., Folęga P., Wieczorek A. N. Determination of the damping characteristics of hydro pneumatic suspension strut. Journal of Measurement in Engineering, Vol. 1, Issue 3, 2013, p. $155-158$.

[15] Konieczny L., Burdzik R., Warczek J. Determinations of shock absorber dumping characteristics taking stroke value into consideration account. Diagnostyka, Vol. 3, 2010, p. 51-54.

[16] Konieczny L., Burdzik R. Comparison of characteristics of the components used in mechanical and non-conventional automotive suspensions. Solid State Phenomena, Vol. 210, 2014, p. 26-31.

[17] Konieczny Ł., Warczek J., Młyńczak J., Zawisza M. Free vibration method for technical condition assessment of automotive shock absorbers. Diagnostic, Vol. 18, Issue 3, 2017, p. 47-53.

[18] Konieczny $\mathbf{L}$. Analysis of simplifications applied in vibration damping modelling for a passive car shock absorber. Shock and Vibration, 2016, http://dx.doi.org/10.1155/2016/6182847.

[19] Lanzendoerfer J. Reaserch of Passenger Cars. WKiŁ, Warszawa, 1997.

[20] Reński A. Car Building: Suspension, Handling and Steering Subsystems. Oficyna Wydawnicza Politechniki Warszawskiej, Warszawa, 2004.

[21] Warczek J., Burdzik R., Peruń G. The method for identification of damping coefficient of the trucks suspension. Key Engineering Materials, Vol. 588, 2014, p. 281-289. 